\title{
Establishing Problem Spaces and Boundaries during Small Group Work on a Contextualized Problem
}

\author{
Rebecca McGraw \\ University of Arizona, USA \\ Cody L. Patterson \\ Texas State University, USA
}

In this study, we examine how United States (U.S.) grades 6-12 teachers working together on a contextualized mathematics problem negotiate issues arising from the ill-structured nature of the problem such as what assumptions one may make, what real-world considerations should be taken into account, and what constitutes a satisfactory solution. We conceptualize the process of negotiating these questions as the construction of a "problem space," characterized by the boundary between considerations deemed relevant or essential to the problem and ones thought to be beyond the scope of the problem. We use data from group discussions of the problem to consider ways in which problem spaces are co-constructed by learners, instructors, and problem authors and how these problem spaces evolve over time. Using Palm's authenticity framework (2002; 2006; 2008), we analyze and describe ways in which more or less authentic aspects of the problem intersected with the construction of problem spaces and boundaries. Lastly, we conclude by discussing implications of these findings for the design and implementation of contextualized mathematics problems with middle and high school teachers, and, potentially, with middle and high school students.

Keywords: Contextualized math problems, authenticity, group problem solving, problem spaces and boundaries.

In this paper, we consider the work of two small groups of U.S. grades 612 teachers on a single mathematics problem. The problem is contextualized and open-ended and involves some aspects of both problem-solving and mathematical modeling. Lesh and Zawojewski (2007) define problem-solving as:

The process of interpreting a situation mathematically, which usually involves several iterative cycles of expressing, testing and revising mathematical interpretations - and sorting out, integrating, modifying, revising, or refining clusters of mathematical concepts from various topics within and beyond mathematics. (p. 782) 
The problem we discuss in this paper requires the integration of multiple mathematical concepts, as well as interpretation, modification, and revision of ideas within and outside of mathematics. With respect to mathematical modeling, when learners work on a problem involving a real-world context, part of the problem-solving process may involve the construction of mathematical models, or systems of objects, relationships, and rules that can explain or predict the behavior of other systems (Doerr \& English, 2003). Although we do not claim that the problem discussed in this paper is a modeling problem per se, participants did engage in some aspects of the modeling process (e.g., developing a model and interpreting solutions) as they solved the problem. The problem used in this study is contextualized and illstructured (Jonassen, 1997), and requires that the learner find and use information from the real world (the specific problem used is described in the Method section of this paper; additional details about the problem can be found in McGraw and Patterson (2017).

\section{Conceptual Framework}

Our focus in this article is on the negotiation of problem spaces. We define a "problem space" as the collection of mathematical ideas and classroom and real-world issues and resources that learners take up and use as part of their solution process. These ideas, issues, and resources become visible as the boundaries of the problem spaces are constructed and explicitly negotiated. For example, while working on the problem of designing an enclosure with the greatest possible area given a fixed perimeter, a learner may decide (by themselves or in negotiation with a teacher) that they only need to consider rectangular shapes. This decision about the problem boundary leads to a problem space that includes rectangles but no other shapes. By investigating the development of problem boundaries, we hope to better understand the ways in which problem spaces are created and how they evolve, as well as surface implicit assumptions about problem spaces and boundaries that we may take into our own mathematics teaching.

We assume that learners' problem-solving work is situated within particular mathematics classroom contexts, with associated norms and expectations that will influence the negotiation of the problem spaces together with learners' previous experiences in mathematics classrooms (Wernet, 2017). We assume that learners' beliefs about mathematics and their mathematical and school-learner identities will influence how problem spaces/boundaries are established, as will power and authority relationships among learners and between teachers and learners. Lastly, we assume that the establishment of problem spaces is an ongoing negotiation that takes place among learners, teachers, and "animated others" such as problem authors or representatives of the real world (e.g., people in a town, a business owner, etc.). 
With respect to previous research on the use of contextualized problems in mathematics classrooms, Wernet (2017) provided the field with an extended literature review, concluding that,

$[R]$ esearch shows that students can experience difficulty determining the role of the context in solving a problem in both traditional story problems and more open-ended tasks. ... even meaningful contexts drawn from students' everyday lives can challenge beliefs about what it means to do mathematics, the applicability of standard mathematical procedures, and the authority students have over strategy choice (Civil, 2002; Tomaz \& David, 2015) .... These complexities point to the importance of the teacher's role in selecting contextual tasks and helping achieve their intended purposes by supporting students in making sense of problem scenarios. ... A theme throughout studies on implementing contextual problems in ways that successfully build on students' everyday knowledge is to create a climate in which that knowledge is accepted and validated - to make contexts an explicit part of classroom discussion (Bonotto, 2007; Brenner, 2002; Chapman, 2006; Chapman, 2007; Nasir et al., 2008). (p. 72)

Thus, it is not enough to create and utilize contextualized tasks; rather, teachers must consider the ways their interactions with students serve to create and reify problem spaces and boundaries. Further, teachers (and researchers) must recognize that "students" is not a homogeneous category and that the ways contextualized problems are implemented in classrooms can have differential impacts across student populations (e.g., Lubienski, 2000).

Recent studies by educational psychologists and others have extended our understanding of children's experiences solving word problems in mathematics (e.g., Fuchs et al., 2016; Fuchs, Gilbert, Fuchs, Seethaler \& Martin, 2018; Swanson, Lussier, \& Orosco, 2013; Walkington, Clinton, \& Shivraj, 2018). For example, Fuchs et al. (2016) found a strong correlation between word problem-solving skills and pre-algebraic knowledge (e.g., understanding the equal sign as relational, rather than as a command to calculate) among U.S. $4^{\text {th }}$ grade students, and, in related research, Fuchs et al. (2018) found stronger connections between language skills and word problem-solving skills than between calculational skills and word problemsolving skills among U.S. second grade students. The language skills needed to comprehend word problems depend, in part, on the readability of the problems themselves, and Walkington, Clinton, and Shivraj (2018) found that problem readability factors - such as length, word difficulty, and pronouns differentially and negatively impacted struggling students. These researchers call for readability to be explicitly considered in the design of contextualized word problems in mathematics.

In addition to the factors described previously, the nature of the mathematical problem, as written and as implemented, should be considered in terms of its authenticity (Palm, 2008; Wiggins, 1993). According to Palm, 
To study the concordance between a school task and a real-life task situation it is useful to have a definition of what constitutes such a relationship. That is, in more precise terms what we mean with a school task that well emulates a real-life task situation. ... [T] [Te term authentic is used for this relationship and the term is used in relation to the out-of-school situation that is described in the task, the task context. (2008, pp. 39-40)

The list below summarizes key aspects of task authenticity as described by Palm $(2002,2006,2008)$. When these aspects are present to a higher degree, then the mathematical problem is a better simulation of the real-world situation it is intended to represent.

- Event: Has the event described in the problem occurred in the real world or is the event likely to occur in the real world?

- Question: Are the question(s) posed in the problem ones that would be posed in the real world, given the event that has occurred?

- Purpose: Is the purpose of answering the questions posed and solving the problem made clear to learners? [An underlying assumption is that work on problems in the real world is situated within, and results are judged against, specific goals.]

- Language Use: Does the language-related work learners need to do to solve the problem, for example, understanding terminology and reading and interpreting text, mirror that which would be required when solving the problem in the real world?

- Information/Data:

Existence: Is similar information available to learners as would be available to individuals solving the problem in the real word?

Realism: Are the numbers and values in the problem realistic?

Specificity: Is specific information provided or available (e.g., subjects, objects, places)? (summarized based on Palm (2002, 2006, 2008)).

These aspects of authenticity are useful in two ways - first, they provide a backdrop against which to analyze mathematical problems themselves, and second, they help us to consider how authenticity relationships between classroom problems and real-world situations may influence the ways that learners interact with the problems and the nature of group dynamics when learners work together to solve them. That is, we can investigate the ways issues of authenticity arise during task implementation.

A gap in the literature currently exists with respect to understanding the ways that teachers, students, or others, interpret mathematical problems that are situated in "real-world" contexts but are to be solved in a mathematics classroom context. This interpretative work includes comprehension of the words that make up the problems, and also, by necessity, involves the placement of boundaries around the problem as it is being solved. Task authenticity is a factor that may interact with boundary placement and is 
therefore considered in this study as well. We attempt to address this gap through our investigation of the following research questions:

1. How do mathematics teacher-learners, engaged in an ill-structured contextualized problem, negotiate the problem space?

2. What boundaries do the teachers establish and how are they determined? How do the boundaries evolve throughout the problemsolving process?

\section{The Water Shortage Problem}

The Water Shortage Problem (Figure 1), designed by one of the authors of this paper, requires learners to answer a practical question (how many trucks are needed to deliver water to a town) by analyzing rates of water consumption and delivery rather than absolute amounts. The information card intentionally leaves some essential questions unanswered, such as how much water a truck can carry, and how much water each person will need. The purpose of providing incomplete information is to stimulate discussion among participants about what quantities are relevant to the problem's solution and to encourage learners to seek information from sources external to the activity.

The town of Squareville (population 25,600) relies on a nearby lake for drinking water. The water has been tainted due to an industrial accident. The lake can be cleaned, but it will take about two weeks to do so. In the meanwhile, the state plans to use trucks to send clean water to Squareville from a town 23 miles [37 $\mathrm{km}]$ away. How many trucks will the state need?

In order to proceed to the next task, you (the person holding this card) must give a referee a convincing argument answering this question.

Figure 1. The water shortage problem.

In order to foster interdependence among groups of learners (Cohen \& Lotan, 2014), the information contained on the problem statement (Figure 1) is only made available to one group member, who is designated the leader. The leader may share the information on the card orally with other group members and help guide the discussion, but the leader is not permitted to write anything down or share the card. Other group members may write down their thoughts and mathematical work but are not allowed to see the card. Once the group reaches a consensus solution, the leader must explain it to a teacher/instructor (referred to as the referee), who may then ask follow-up questions of the other group members. Because the leader cannot perform calculations and other members have no direct access to the information on the card, group members must communicate about their overall problem- 
solving strategy as well as the details of the solution so that the leader can clearly describe the group's work to the referee.

With respect to authenticity, the event, water contamination due to an industrial accident, certainly occurs in the real world and the question (How many trucks will the state need?) is one that could reasonably be asked. The language used in the problem statement and to solve the problem as implemented in this study bear some similarities to the real world. However, the technical language that would likely be needed and used to solve the problem in the real world is largely absent from the problem-solving activity. With regard to purpose, learners were not given specific criteria against which their solutions would be judged but were given a purpose in terms of the water shortage scenario and the potential need for trucks within that scenario. The Water Shortage Problem is least authentic in terms of the information/data provided to learners; in the real world, individuals would have access to much more data (Existence) than was the case in the classroom, and they would have detailed information (Specificity) about the needs and resources of an actual town, including emergency measures or guidelines in place for potential water contamination issues.

\section{Method}

In the summer of 2015, the authors and one other instructor taught an 80-hour mathematics content-focused professional development course to 33 grades 6-12 mathematics teachers in the southwestern United States. Teachers spent most of their time during the course working in small groups on problems and activities meant to highlight key ideas in the U.S. grades 6-12 mathematics curriculum, including ratios and proportions, rates of change, algebra and function concepts, and similarity. The Water Shortage Problem was implemented during the first part of the course.

During the problem implementation, we collected video and audio recordings of two groups, each consisting of three grades 6-8 teachers and one grades 9-12 teacher. The video camera was placed so as to view the entire group, which allowed us to clearly document interactions among group members and between group members and the instructors but did not allow us to see what each teacher wrote down as the group worked. Group 1 spent 22 minutes on the problem, and Group 2 spent 30 minutes.

To analyze the group interactions, we used an interrelated set of theoretical constructs including the concept of problem "spaces" and "boundaries," and aspects of task authenticity as described by Palm (2002, 2006, 2008). From a pragmatic perspective (Hammond, 2013; Morgan, 2014; Savin-Baden \& Major, 2013), we were interested in the utility of these constructs in terms of their interpretative power. Our analysis methodology consisted of independent, repeated viewing of the video/audio data which 
allowed for the application of theoretic constructs as well as the identification of emergent themes.

After each author independently viewed the video/audio recordings and identified instances in which participants and instructors appeared to question or negotiate the boundaries of the problem, we attempted to identify factors in the group discussion, the instructor's comments, or the design of the task that may have influenced the group's decision about how to define the problem space. We repeatedly met together to compare analyses and come to a consensus on any discrepancies. As this study was exploratory in nature, our work at this stage consisted of careful deconstruction of the group interactions, coupled with conversations about the nature and applicability of the constructs of problem "space" and "boundaries."

Our analysis of the relationships between problem authenticity (Palm 2006, 2008) and the establishment of problem spaces and boundaries occurred as a secondary stage of analysis during which we identified ways in which aspects of task authenticity were represented in the problem itself and how these aspects appeared to interact with the establishment of problem boundaries during group work. We proceeded with this secondary analysis in a similar manner to the initial analysis; that is, we began with independent viewings of the data and then proceeded to develop a consensus of meanings and interpretations through conversation between the two authors and reviewing of the data.

\section{Results}

In each of the two groups, the teacher-learners worked gradually toward a consensus solution, making assumptions about the situation described and making preliminary estimates, and refining these estimates to produce a reasonable and practically feasible solution. Neither of the groups produced multiple solutions; rather, they worked as teams to develop and refine single solutions to the task. Along the way, each group confronted questions about which elements of the real-world situation should be taken into account and which considerations lay beyond their co-constructed boundaries. In this section, we analyze each group's negotiation of the problem space and observe how this space evolved over the duration of the group's work on the problem. All names used below are pseudonyms.

\section{Shifting Responsibility for Boundary-Setting: Group 1}

Vicki, the leader of Group 1, introduced the problem by reading her card aloud to her teammates Tina, Kenny, and Nalda. Shortly after reading the card, Vicki questioned whether the group was allowed to consider information not on the card (Table 1). The question of how much discretion the group has in negotiating problem conditions and goals occurred again later, as Vicki asked whether the question was about "efficiency" or about how many trucks 
the state should send. Upon asking this, Vicki said, "I don't know how far we're allowed to take this," suggesting that authority for determining problem boundaries lay at least partially outside of the group itself. This comment also suggests that the purpose of the task, an aspect of authenticity, was not made clear. We hypothesize that many teachers' prior experiences with contextual problems (as teachers or learners) may consist mainly of problems for which the boundaries are largely pre-determined by the problem statement, or are structured by the teacher.

The group ultimately developed estimates for the number of trucks needed in two different scenarios: if the state sends large tanker trucks, and if it sends smaller water trucks. The group's initial approach assumed that each truck would make only one trip per day, and that each resident of the town would receive 90 gal [341 L] of water per day. This led to an estimate of 221 tankers per day. At this point, Nalda raised the concern that sending 221 tankers per day would not be realistic, and suggested a model in which each tanker makes several trips per day. In raising this concern, Nalda did not appear to attend particularly to one aspect of authenticity within the data the group had gathered about what consumption, whether 90 gal $(341 \mathrm{~L})$ per person per day was a realistic amount during a crisis, but she did choose to consider the realism (or lack thereof) of the data [221 tankers] the group was producing as a possible solution.

The group initially dismissed Nalda's suggestion (Table 1), claiming that the problem was to estimate the number of truck (or tanker) loads, not the number of trucks or tankers. Although the problem statement referenced the "number of trucks," it seems reasonable that knowing the number of truckloads would be useful in the real world. Later during the group's work, Nalda tried again to focus the group's attention on trucks versus truckloads, when she stated, "I feel like they give us the 23 miles [37 km] for us to estimate how many trucks." In this instance, Nalda appealed to an external source (i.e., the problem author) in order to negotiate a problem boundary with the other group members, and was successful in doing so. It is interesting that Nalda's appeal to an inauthentic (compared to the real world) aspect of the group's solution, 221 tankers, was not compelling to the rest of the group, whereas her appeal to an inauthentic (compared to the real world) aspect of school mathematics, that all the information given will be used, was compelling.

We note here that, for Group 1, interpreting the implicit intentions of the problem author appears to be a central part of their effort to negotiate the problem boundaries, and thus the problem space. The group also attended, in some instances, to whether a particular approach or solution was realistic. At the same time, group members did not attend to what would be a realistic amount of water per person per day during a crisis, and group members (other than Nalda) seemed willing to accept a solution that called for an unrealistic number of tankers or trucks. Overall, in this data, we found multiple examples 
of this push-pull between school-based norms for contextualized problems (e.g., interpreting the author's intentions) and the desire to find a realistic solution.

\section{Table 1}

\section{Interactions Influencing the Problem Space for Group 1}

\begin{tabular}{l}
\hline \multicolumn{1}{c}{ Interaction } \\
\hline Vicki: Are we allowed to \\
extrapolate outside of what is \\
on the card? We would need to \\
know how much a truck could \\
carry, average family size...
\end{tabular}

Nalda: Are we looking for realistic solutions to this? Because the state isn't going to pay for that many [221 trucks] a day... each truck can make four trips...

Kenny: What if they don't have tankers, they have an average water truck?

Tina: So, did we answer the question?

Vicki: I feel like we would need more parameters though to be able to really integrate the 23 miles [ $37 \mathrm{~km}$ ].

Nalda: I feel like they give us the 23 miles [ $37 \mathrm{~km}$ ] for us to estimate how many trucks.

Kenny: How long is a tanker? Nalda: I don't know.

...

Kenny: Where are they storing this?

Nalda: Well, water towers.

Kenny: I'm just thinking/

Nalda: /Half an hour to fill, half an hour to get there...
Group begins to consider multiple trips per truck.

Tina pulls up a picture of a tanker on her phone and shows the group. Nalda redirects the group's attention to the calculation of the number of trucks.

\section{Possible causes of interaction}

Contextual problems

encountered in school often provide the information that is needed; no more, no less. In this setting, the group must negotiate the boundaries of the problem space.

Nalda believes that in this case, issues of realism should at least be considered. Nalda uses the pronoun "we," while Vicki uses the pronoun "they."

Group considers both scenarios and produces an estimate for each.

The problem is ambiguous on the issue of which type of truck the state will use. The group does not have the resources to resolve this ambiguity but is willing to manage it as a condition of the problem. Task design: Tina cannot look at the card with the question on it.

Nalda pushes the group not to set aside the distance information. She reframes the problem so as to put group members inside the real-world situation.

Nalda seems to view Kenny's queries as outside of the problem's boundaries.

\section{The Instructor's Role in Expanding the Problem Space: Group 2}

Vince introduced the problem to his teammates Tobias, Darla, and Violet by summarizing the information on his card rather than reading it 
verbatim. The group immediately began searching the internet on their phones and laptop computers for information relevant to the problem and found that a water truck can carry 5000 gal $[18,927 \mathrm{~L}]$ and that an average person in the U.S. uses between 80 and 100 gal [303 and $379 \mathrm{~L}$ ] of water per day. Based on this information, they obtained an initial estimate of 6450 trucks, which Violet deemed to be "excessive" (Table 2).

Spurred in part by the infeasibility of this estimate, the group began to identify ways they could significantly decrease this estimate. Tobias suggested researching the minimum amount of water a person needs each day; based on his research, the group accepted a much lower estimate of 5 gal [19 L] per person per day. The group then arrived at a more modest estimate of 358 trucks, still reflecting the implicit assumption that each truck will make only one run over the two-week period. Thus, the group accepted one inauthentic aspect of their solution (each truck makes only one trip) while rejecting another (each person can have 90 gal $(341 \mathrm{~L})$ of water per day during a crisis). Because the problem statement lacked specificity and authenticity of purpose, the group and the instructors did not have a shared understanding of how to impose boundaries around the problem space, especially in relation to allowing real-world considerations in the solution process.

The group then presented this solution to Nancy, one of the instructors of the professional development course. Nancy said that the state did not have 358 trucks to spare and that the group should try to determine the minimum number of trucks needed. After she left the group, Violet pointed out that the question did not ask for the least possible number of trucks, and Tobias claimed that Nancy had changed the question.

After this exchange, Tobias suggested considering how many trucks are needed per day (rather than for the entire two-week period); this brought the group's estimate from 358 down to 26 . The group then gradually developed a plan in which six trucks take turns dropping water off at Squareville; at any given time, one truck is in Squareville dropping water, one truck is in the nearby town collecting water, and four other trucks are in transit between the two towns (Table 2).

We observe that as the group worked on the problem, the problem space grew to encompass considerations of how much water a person needs during an emergency and how much water an "average" truck can hold. However, only after Nancy visited the group and encouraged them to develop a more feasible solution did members of the group expand the problem space to include the possibility of having trucks perform multiple runs on the same day. Interpreted through the framework of problem authenticity (Palm 2006, 2008), we conjecture that because two related aspects of authenticity - clarity of purpose and the specificity of information/data provided - were not strongly represented in the problem itself, the teachers were left to impose these aspects. From this perspective, it is reasonable that the group members 
would feel that Nancy had changed the problem, despite having considered the feasibility of the total number of trucks themselves earlier in their work.

\section{Table 2}

\section{Interactions Influencing the Problem Space for Group 2}

\begin{tabular}{|c|c|}
\hline Interaction & Action/response \\
\hline $\begin{array}{l}\text { Violet: Do we know how much } \\
\text { water the trucks hold? Or how } \\
\text { much each person needs? } \\
\text { Vince: No. }\end{array}$ & $\begin{array}{l}\text { Tobias starts to look for } \\
\text { information on the } \\
\text { internet using his tablet. }\end{array}$ \\
\hline $\begin{array}{l}\text { Violet: Are they telling the people } \\
\text { to limit the water? Because I feel } \\
\text { like that would be beneficial. }\end{array}$ & $\begin{array}{l}\text { Tobias determines that } \\
\text { on average, a person } \\
\text { uses between } 80 \text { and } \\
100 \text { gal per day [ } 303 \\
\text { and } 379 \text { L per day]. The } \\
\text { group doesn't pursue } \\
\text { Violet's idea yet. }\end{array}$ \\
\hline $\begin{array}{l}\text { Violet: It's } 80 \text { to } 100 \text { gallons per } \\
\text { day [303-379 L per day], so do we } \\
\text { just want to use } 90 \text { [341]? }\end{array}$ & $\begin{array}{l}\text { Group calculated } 90 \times \\
14 \times 25,600= \\
32,256,000 \text { gal }[122,102 \\
\text { L]. Divided this by } 5000 \\
\text { gal per tanker [18,927 } \\
\text { L] to obtain } 6451 \\
\text { trucks. }\end{array}$ \\
\hline
\end{tabular}

Violet: 6451 trucks, that seems really excessive.

Tobias: Let's see how much a person needs in a day.

Violet: We don't know what limitations have been set for this town.

Nancy: Yeah, well Circleville's also having a water issue, and I just don't have 358 trucks, so what's the minimum number I need?

...

Nancy: So, think just a little more about how many trucks you need. Like what's the minimum number I can give you?

Darla: How long does it take to unload a water truck?

Violet: And how do you decide who gets water first? Are we figuring out the least? Is that the question? The least number? It just said how many trucks need to be sent, it didn't say least!

Vince and Tobias: She changed it.
Possible causes of interaction

The problem cannot be solved without information that is not on the card.

The group seems to feel that limiting water is beyond the boundaries of the problem.

Using the midpoint of a range as an estimator is possibly related to prior experience with school math problems; in this case, it may actually be worthwhile to use the lower end of the range in order to minimize the number of trucks needed.

Initially, Violet seems to view the issue of water rationing as outside the boundaries of the problem. Eventually, the group shifts the boundaries to encompass this question. At this stage, the group presents their solution to Nancy (an instructor) Nancy observes that the group has not incorporated the possibility of trucks making multiple deliveries per day into the problem space; she uses the impracticality of a request for 358 trucks to encourage the group to reconsider the problem boundaries they have constructed.

Group estimates how much time is needed for a delivery cycle and how many cycles are needed per day, and eventually decides upon 6 trucks.
Violet, Tobias, and Vince indicate their belief that they have been asked to enter a different problem space. 


\section{Discussion}

In many cases, there can be a great distance between mathematics as it is done in school and mathematics as it is carried out in the real world. This distance is part of what drives efforts by teachers and curriculum writers to create contextualized scenarios that situate and connect the problem-solving process with the real world. By considering the extent to which these contextualized problems are authentic as written and implemented (Palm 2006, 2008), and analyzing the development of problem spaces and boundaries during implementation, we can add to our understanding of the factors that may influence student engagement and learning around such problems. In the case of teachers solving contextualized problems, it may be useful to also use existing frameworks (e.g., Palm, 2008; Wernet, 2017) to engage them in deconstructing their own experience with a contextualized problem (such as the Water Shortage Problem) as a way to develop knowledge about such tasks, and as a way to develop reflective practices as they implement contextualized tasks in their own classrooms. This represents the next stage of our research.

With regard to the ways authenticity can influence the development of problem spaces, we identified three themes in our data. First, authentic elements of a problem, as written and/or as implemented, can interact with problem boundaries in significant ways. For example, because the problem is about a water shortage, it seems important to use crisis water consumption amounts as opposed to daily average consumption amounts, and the choice of water amounts has a significant effect on the reasonableness of the groups' solutions. Second, inauthentic elements can also lead to negotiations and even disagreements over problem boundaries. We saw this in Group 2 when they claimed that the instructor had changed the problem when she insisted that 358 trucks were not reasonable and asked for a minimum number of trucks. Finding the minimum (or near minimum) number of trucks would be expected in a real-world scenario, but because it was not explicitly requested in the task as written, group members were able to claim that minimizing the number of trucks was outside of the problem space. Lastly, we found that the teachers' expectations about authenticity of contextual problems as a genre of classroom mathematical tasks played an important role in their interactions. At times, this occurred through the posing of meta-level questions (e.g., in Group 1, Vicki asked, "Are we allowed to extrapolate outside of what is on the card?" and Nalda asked, "Are we looking for realistic solutions to this?") while at other times this meant appealing to an understanding of typical school mathematics problems (e.g., when Group 1 worried that some information given in the problem statement had not been used in the solution).

Our analysis of the negotiation of problem boundaries has implications for the practice of designing open-ended problems. In analyzing the groups' work on the Water Shortage Problem, we found that the problem worked as 
intended in at least one respect: both groups originally obtained unfeasibly large estimates for the number of trucks needed, and thus were encouraged (without external feedback) to revise their assumptions. Both groups decided that the problem space should include some consideration of whether the solution obtained was fiscally responsible. Additionally, both groups decided to include some analysis of whether the solution obtained was physically feasible; for example, Group 2 developed a plan in which six trucks rotate in and out of Squareville in succession, dropping off water as they arrive. Thinking about the problem at this level of detail helped the group develop confidence that a solution with six trucks was feasible and would deliver enough water. We posit that ill-structured problems that contain supports for the development of detailed models and that encourage winnowing out unreasonable solutions may support learners in expanding problem spaces to include practical considerations.

In mathematics classrooms, teachers mediate students' problemsolving work in ways that serve to co-construct problem spaces and boundaries, and communicate to students, explicitly or implicitly, how much of the real world to include in their thinking. A mathematics problem may be more or less authentic as written, but aspects of authenticity will be encouraged and repressed as students engage with the problem and with their teacher. In our data, we find an example of the usefulness of two teacher strategies identified by Wernet (2017) who found that positioning and elaborating were useful for making problems more realistic and purposeful for students. Positioning relates to placing oneself and/or others into the problem context and elaborating refers to extending the problem context beyond what is written. In our data, an example of both would be when the instructor, Nancy, says to Group 2 "Circleville's also having a water issue, and I just don't have 358 trucks, so what's the minimum number I need?" Certainly, in at least this one example, Nancy's positioning and elaborating served to introduce additional realism and purpose to the work of Group 2.

We are careful here to make no claim that our findings generalize across mathematics problems or groups of learners. The negotiation of a problem space may look markedly different in the context of a more closedended task, and may also vary according to the age and mathematical background of learners. One may argue that in this particular study the participants' shared familiarity with rate reasoning allowed them to devote additional attention to considering boundary issues such as which quantities in the problem should influence the problem's solution and which should not. Further study, with different types of tasks and with different populations of learners, is needed for a better understanding of how problem spaces develop in different settings. To summarize, limitations of this study include (1) our use of a single problem, the Water Shortage Task, which may have unidentified, idiosyncratic qualities that could limit generalizability, (2) differences between the ways mathematics teachers may interact with problem 
spaces/boundaries (as compared to K-12 students), and (3) the small number of study participants, which again impacts generalizability. Future research could address these limitations by utilizing a larger set of tasks and varying the characteristics of the learners (teachers or K-12 students).

With respect to future research, several avenues may be productive to pursue. First, and as previously mentioned, studying how teachers themselves analyze the authenticity of written tasks and consider problem spaces/boundaries as they plan for instruction. Second, engaging various types of learners in the Water Shortage Problem, or similar task, in order to examine differences in learner interpretations of space/boundaries around a particular contextualized task. Lastly, it could be informative to create a set of mathematical problems of varying degrees of authenticity around a single mathematical topic and investigate how learners may differ in their negotiation of problem space/boundaries depending on the authenticity of the written problem.

We conclude this report by highlighting two ways in which the problem space of the Water Shortage Problem may communicate with the broader space of learners' real-world experience. Since the time of the creation of this problem, water system contamination has occurred in places in the U.S. such as Flint, Michigan and Corpus Christi, Texas, and water crises occur around the world for a variety of reasons (e.g., the war in Yemen). In subsequent implementations of the Water Shortage Problem, the authors have noticed that learners who have experienced water contamination sometimes interact differently with the problem; they are more knowledgeable about how water is actually distributed during a water crisis, and more attentive to logistical issues such as how a town should time and manage water collection. We offer this as an example of learners' real-world experiences increasing the authenticity of the problem space. As an example of the problem space speaking back to the broader world in which the learners live, consider the following comment made by Violet: "If this [ 90 gal per day or $341 \mathrm{~L}$ ] is what I use on a regular basis and this [ 5 gal or $19 \mathrm{~L}$ ] is what I use in a disaster... like... I feel like this is the disaster!" Seeing the disparity between everyday water usage in the U.S. and recommended water usage during an emergency may heighten learners' awareness of the possibility of decreasing daily water consumption and using natural resources at a more sustainable rate.

Author's Note: This paper is based on a paper by the authors that was included in the proceedings of the 2017 Psychology of Mathematics Education - North America (PME-NA) annual conference. This paper represents significant additions to the original study in the areas of conceptual framing, analysis, and interpretation of findings. 


\section{References}

Bonotto, C. (2007). How to replace word problems with activities of realistic mathematical modeling. In W. Blum, P. L. Galbraith, H.-W. Henn, \& M. Niss (Eds.), Modelling and applications in mathematics education: The 14th ICMI Study (pp. 185-192). New York, NY: Springer.

Brenner, M. E. (2002). Everyday problem solving and curriculum implementation: An invitation to try pizza. Journal for Research in Mathematics Education. Monograph 11, Everyday and Academic Mathematics in the Classroom, 11, 63-92. doi:10.2307/749965

Chapman, O. (2006). Classroom practices for context of mathematics word problems. Educational Studies in Mathematics, 62(2), 211-230. doi:10.1007/s10649-006-7834-1

Chapman, O. (2007). Mathematical modeling in high school mathematics: Teachers' thinking and practice. In W. Blum, P. L. Galbraith, H. W. Henn, $\&$ M. Niss (Eds.), Modelling and applications in mathematics education, The 14th ICMI study (pp. 325-332). New York, NY: Springer.

Civil, M. (2002). Chapter 4: Everyday mathematics, mathematicians' mathematics, and school mathematics: Can we bring them together? Journal for Research in Mathematics Education Monograph, 11, 40-62. doi:10.2307/749964

Cohen, E. G., \& Lotan, R. A. (2014). Designing groupwork: Strategies for the heterogeneous classroom third edition. New York, NY: Teachers College Press.

Doerr, H. M., \& English, L. D. (2003). A modeling perspective on students' mathematical reasoning about data. Journal for Research in Mathematics Education, 34(2), 110-136.

Fuchs, L. S., Gilbert, J. K., Fuchs, D., Seethaler, P, M., \& Martin, B. N. (2018). Text comprehension and oral language as predictors of wordproblem solving: Insights into word-problem solving as a form of text comprehension. Scientific Studies of Reading, 22(2), 152-166. https://doi.org/10.1080/10888438.2017.1398259

Fuchs, L. S., Gilbert, J. K., Powell, S. R., Cirino, P. T., Fuchs, D., Hamlett, C. L., . . Tolar, T. D. (2016). The role of cognitive processes, foundational math skill, and calculation accuracy and fluency in word-problem solving versus prealgebraic knowledge. Developmental Psychology, 52(12), 20852098. http://dx.doi.org/10.1037/dev0000227

Hammond, M. (2013). The contribution of pragmatism to understanding educational action research: Value and consequences. Educational Action Research, 21(4), 603-618. doi: 10.1080/09650792.2013.832632

Jonassen, D. H. (1997). Instructional design models for well-structured and ill-structured problem-solving learning outcomes. Educational Technology Research and Development, 45(1), 65-94. 
Lesh, R., \& Zawojewski, J. (2007). Problem solving and modeling. Second handbook of research on mathematics teaching and learning, 2, 763-804.

Lubienski, S. T. (2000). Problem solving as a means toward mathematics for all: An exploratory look through a class lens. Journal for Research in Mathematics Education, 31(4), 454-482. doi:10.2307/749653

McGraw, R., \& Patterson, C. L. (2017). Contextualized mathematics problems and transfer of knowledge: Establishing problem spaces and boundaries. In E. Galindo \& J. Newton (Eds.), Proceedings of the Thirty-Ninth Annual Meeting of the North American Chapter of the International Group for the Psychology of Mathematics Education (pp. 661-668). Indianapolis, IN: Hoosier Association of Mathematics Teacher Educators.

Morgan, D. L. (2014). Pragmatism as a paradigm for social research. Qualitative Inquiry, 20(8), 1045-1053.

Nasir, N. S., Hand, V., \& Taylor, E. V. (2008). Culture and mathematics in school: Boundaries between 'cultural' and 'domain' knowledge in the mathematics classroom and beyond. Review of Research in Education, 32, 187-240. doi:10.3102/0091732X07308962

Palm, T. (2002). The realism of mathematical school tasks: Features and consequences. Doctoral dissertation, Department of Mathematics, Umeå University, Sweden.

Palm, T. (2006). Word problems as simulations of real-world situations: A proposed framework. For the Learning of Mathematics, 26(1), 42-47.

Palm, T. (2008). Impact of authenticity on sense making in word problem solving. Educational Studies in Mathematics, 67, 37-58. doi 10.1007/s10649-007-9083-3

Savin-Baden, M., \& Major, C. (2013). Qualitative research: The essential guide to theory and practice. New York, NY: Routledge.

Swanson, H. L., Lussier, C. M., \& Orosco, M. J. (2015). Cognitive strategies, working memory, and growth in word problem solving in children with math difficulties. Journal of Learning Disabilities, 48(4), 339358. https://doi.org/10.1177/0022219413498771

Tomaz, V. S., \& David, M. M. (2015). How students' everyday situations modify classroom mathematical activity: The case of water consumption. Journal for Research in Mathematics Education, 46(4), 455-496. doi:10.5951/ jresematheduc.46.4.0455

Walkington, C., Clinton, V., \& Shivraj, P. (2018). How readability factors are differentially associated with performance for students of different backgrounds when solving math word problems. American Educational Research Journal, 55(2), 362-414. doi: 10.3102/0002831217737028

Wernet, J. L. W. (2017). Classroom interactions around problem contexts and task authenticity in middle school mathematics. Mathematical Thinking and Learning, 19(2), 69-94. doi: 10.1080/10986065.2017.1295419 
Wiggins, G. (1993). Assessment: Authenticity, context and validity. Phi Delta Kappan, 75(3), 200-214.

\section{Authors:}

Rebecca McGraw, Associate Professor, Department of Mathematics, University of Arizona, 617 N. Santa Rita Ave., Tucson, AZ 85721. Email: rmcgraw@math.arizona.edu

Cody L. Patterson, Assistant Professor, Department of Mathematics, Texas State University, 601 University Dr., San Marcos, TX 78666. Email: cp46128@txstate.edu 